\title{
From Total Mesorectal Excision to Organ Preservation for the Treatment of Rectal Cancer
}

\author{
Seong Kyu Baek \\ Department of Surgery, Keimyung University Dongsan Medical Center, Keimyung University School of Medicine, Daegu, Korea
}

\section{See Articles on Page 65-71, 83-93}

The current standard treatment for rectal cancer is total mesorectal excision (TME) with or without neoadjuvant chemoradiotherapy (CRT) according to the patient's initial staging [1]. The National Comprehensive Cancer Network guidelines recommend excision without neoadjuvant CRT for the treatment of early rectal cancer (T1-2, N0), and neoadjuvant CRT followed by TME for the treatment of locally advanced rectal cancer [2]. A 54\%-75\% partial response and $8 \%-27 \%$ pathologically-complete response can be achieved through neoadjuvant CRT [3-5]. Rectal cancer response to CRT varies, but earlier stage tumors respond better than more advanced tumors. The degree of tumor downstaging after neoadjuvant CRT is associated with patient prognosis and disease-free survival (DFS) $[6,7]$.

In this issue, Kim et al. [8] reported the results of a 14-year experience at a large-volume single institution in which the oncologic outcomes in patients undergoing neoadjuvant CRT and TME for the treatment of locally advanced rectal cancer were evaluated. The pathologic complete response ( $\mathrm{pCR})$ rate $(23.7 \%, 111$ patients) in this study was within the ranges reported in previous studies. The 5 -year DFS and overall survival (OS) of patients with pCR (ypT0N0) were $92.5 \%$ and $94.5 \%$, respectively. The pathologic stage after neoadjuvant CRT was the most statistically significant independent predictor of OS and DFS in the multivariate analysis [8].

However, TME is associated with high morbidity rates and impaired functional outcomes. Tumor sterilization after neoadjuvant

Correspondence to: Seong Kyu Baek, M.D.

Department of Surgery, Keimyung University Dongsan Medical Center, Keimyung University School of Medicine, 1035 Dalgubeol-daero, Dalseo-gu, Daegu 42601, Korea

Tel: +82-53-258-7876, Fax: +82-53-258-4708

E-mail:sgbeak@dsmc.or.kr

ORCID code: https://orcid.org/0000-0001-6427-8675

(C) 2019 The Korean Society of Coloproctology

This is an open-access article distributed under the terms of the Creative Commons Attribution NonCommercial License (http://creativecommons.org/licenses/by-nc/4.0) which permits unrestricted noncommercial use, distribution, and reproduction in any medium, provided the original work is properly cited.
CRT has led to a growing interest in alternative strategies for treating rectal cancer. Organ preservation, by use of observation (watch-and-wait) or local excision, is a new concept for patients with rectal cancer who received neoadjuvant CRT [9]. For patients with a complete or good clinical response, local excision or observation are both options [10].

The ACOSOG Z6041 trial reported successful organ preservation in patients with cT2N0 tumors treated by local excision after CRT with $5 \%$ local recurrence and $88 \%$ survival at 3 years [11]. The GRECCAR 2 trial reported the results of a randomized clinical trial comparing conventional TME with local excision in patients who responded well to CRT for the treatment of cT2-3N0-1 distal rectal cancer. Although this trial did not demonstrate the superiority of local excision over TME in terms of morbidity, longterm effects, or oncological outcomes, organ preservation was achieved in $46 \%$ of patients with acceptable 3-year local recurrence and DFS [12]. Stijns et al. [13] reported the results of a multicenter feasibility study that explored long-term oncological and functional outcomes of CRT followed by organ sparing local excision in patients who responded well to CRT for the treatment of distal rectal cancer in cT1-3N0. The actual 5-year local recurrence rate was $7.7 \%$, with 5-year DFS and OS rates of $81.6 \%$ and $82.8 \%$, respectively. Organ preservation was achieved in $64 \%$, with acceptable health-related quality of life. However, major low anterior resection syndrome was experienced in 50\% [13].

Until now, CRT followed by local excision in patients who respond well to CRT has been an oncologically-acceptable organpreserving strategy for distal rectal cancer, especially for primarily resectable cancer, although local excision is associated with some morbidity and impairment of bowel function. After clinical complete response (cCR) or near $\mathrm{cCR}$, the role of local excision remains controversial.

This was explored by Park et al. [14] in this issue, in which the results of a large volume retrospective study that evaluated the oncological outcomes of 2 types of organ-preserving approaches, observation (watch-and-wait) or local excision, for rectal cancer in patients who showed good clinical response after CRT are reported. Organ preservation was achieved in $94.6 \%(n=70)$ of patients with favorable oncologic outcomes. The 5 -year OS and DFS were 
$93.3 \%$ and $69.8 \%$, respectively, in the observation group, and $92 \%$ and $84.6 \%$, respectively, in the local excision group. The rate of morbidity for local excision after CRT was found to be acceptable (23\%), and the most common morbidity was anal pain (16\%).

Among physicians treating rectal cancer, organ preservation is a field of active clinical research with many questions.

Although oncological outcomes appear to be similar between organ-preserving approaches and radical TME, the organ-preserving strategy has a risk of local recurrence and regrowth [15]. Therefore, the oncological safety of the organ-preserving approach is supported by the success of salvage treatment [16]. Evidence for the safety of an organ-preserving approach in patients with a clinical good response to CRT is increasing, and organ preservation has become an attractive alternative in select patients with rectal cancer.

\section{CONFLICT OF INTEREST}

No potential conflicts of interest relevant to this article were reported.

\section{REFERENCES}

1. Bosset JF, Collette L, Calais G, Mineur L, Maingon P, RadosevicJelic $\mathrm{L}$, et al. Chemotherapy with preoperative radiotherapy in rectal cancer. N Engl J Med 2006;355:1114-23.

2. National Comprehensive Cancer Network. Recent Updates to NCCN Clinical Practice Guidelines in Oncology (NCCN Guidelines) [Internet]. Fort Wathington (PA): National Comprehensive Cancer Network; c2018 [cited 2019 Apr 8]. Available from: https:// www.nccn.org/professionals/physician_gls/recently_updated. aspx.

3. Sauer R, Liersch T, Merkel S, Fietkau R, Hohenberger W, Hess C, et al. Preoperative versus postoperative chemoradiotherapy for locally advanced rectal cancer: results of the German CAO/ARO/ AIO-94 randomized phase III trial after a median follow-up of 11 years. J Clin Oncol 2012;30:1926-33.

4. Kapiteijn E, Marijnen CA, Nagtegaal ID, Putter H, Steup WH, Wiggers T, et al. Dutch Colorectal Cancer Group. Preoperative radiotherapy combined with total mesorectal excision for resectable rectal cancer. N Engl J Med 2001;345:638-46.

5. Maas M, Nelemans PJ, Valentini V, Das P, Rodel C, Kuo LJ, et al. Long-term outcome in patients with a pathological complete response after chemoradiation for rectal cancer: a pooled analysis of individual patient data. Lancet Oncol 2010;11:835-44.

6. Kim NK, Baik SH, Seong JS, Kim H, Roh JK, Lee KY, et al. Oncologic outcomes after neoadjuvant chemoradiation followed by curative resection with tumor-specific mesorectal excision for fixed locally advanced rectal cancer: Impact of postirradiated pathologic downstaging on local recurrence and survival. Ann Surg 2006;244:1024-30.

7. Yeo SG, Kim DY, Park JW, Choi HS, Oh JH, Kim SY, et al. Stageto-stage comparison of preoperative and postoperative chemoradiotherapy for T3 mid or distal rectal cancer. Int J Radiat Oncol Biol Phys 2012;82:856-62.

8. Kim MJ, Jeong SY, Park JW, Ryoo SB, Cho SS, Lee KY, et al. Oncologic outcomes in patients who undergo neoadjuvant chemoradiotherapy and total mesorectal excision for locally advanced rectal cancer: a 14-year experience in a single institution. Ann Coloproctol 2019;35:83-93.

9. Baxter N, Garcia-Aguilar J. Organ preservation for rectal cancer. J Clin Oncol 2007;25:1014-20.

10. Habr-Gama A, Perez RO, Nadalin W, Sabbaga J, Ribeiro U Jr, Silva e Sousa AH Jr, et al. Operative versus nonoperative treatment for stage 0 distal rectal cancer following chemoradiation therapy: long-term results. Ann Surg 2004;240:711-8.

11. Garcia-Aguilar J, Renfro LA, Chow OS, Shi Q, Carrero XW, Lynn $\mathrm{PB}$, et al. Organ preservation for clinical T2N0 distal rectal cancer using neoadjuvant chemoradiotherapy and local excision (ACOSOG Z6041): results of an open-label, single-arm, multi-institutional, phase 2 trial. Lancet Oncol 2015;16:1537-46.

12. Rullier E, Rouanet P, Tuech JJ, Valverde A, Lelong B, Rivoire M, et al. Organ preservation for rectal cancer (GRECCAR 2): a prospective, randomised, open-label, multicentre, phase 3 trial. Lancet 2017;390:469-79.

13. Stijns RC, de Graaf EJ, Punt CJ, Nagtegaal ID, Nuyttens JJ, van Meerten E, et al. Long-term oncological and functional outcomes of chemoradiotherapy followed by organ-sparing transanal endoscopic microsurgery for distal rectal cancer: The CARTS Study. JAMA Surg 2019;154:47-54.

14. Park IJ, Lee JL, Yoon YS, Kim CW, Lim SB, Yu CS, et al. Oncologic outcomes of organ preserving approaches in patients with rectal cancer treated with preoperative chemoradiotherapy. Ann Coloproctol 2019;35:65-71.

15. Dossa F, Chesney TR, Acuna SA, Baxter NN. A watch-and-wait approach for locally advanced rectal cancer after a clinical complete response following neoadjuvant chemoradiation: a systematic review and meta-analysis. Lancet Gastroenterol Hepatol 2017;2: 501-13.

16. Sao Juliao GP, Karagkounis G, Fernandez LM, Habr-Gama A, Vailati BB, Dattani M, et al. Conditional survival in patients with rectal cancer and complete clinical response managed by watch and wait after chemoradiation: recurrence risk over time. Ann Surg 2019 Mar 26 [Epub]. https://doi.org/10.1097/SLA.0000000000003286. 